\title{
Research on Low-Power Fresh Water Extraction Device of Automatic Replenishment
}

\author{
Yilin Song ${ }^{1}$ \\ ${ }^{1}$ School of Energy, Power and Mechanical Engineering, North China Electric Power University, \\ Beijing, 102206
}

\begin{abstract}
Keywords: Desalination, automatic optical tracker, collectors, water level adjustment, coil heat exchanger
\end{abstract}

\begin{abstract}
The main purpose of this system is to use solar energy to desalinate seawater and brackish water, to make efficiently use of solar energy and produce a certain amount of fresh water. The system includes collector with automatic optical tracker, generator, water tank, coil heat exchanger, telescopic inlet valve, water level regulator boxes and other devices. The system uses an open heat pipe design, with collector driven by stepper motor for automatic optical tracker, so as to maintain a high collection efficiency. By water level regulator boxes to adjust water level automatically and control the water level within the generating device, to get a high evaporation rate. Coil heat exchanger uses steam condensation heat to warm up the seawater and brackish water, to further improve energy efficiency and achieve the efficient use of energy cascade.
\end{abstract}

\section{Background and design principles}

China is a country with severe drought and water shortage, and per capita is only 2300 cubic meters, only a quarter of the world average, and it is one of the 13 poorest countries in the world in the aspect of water resources per people. China's current energy consumption structure is still coal-based, high dependent on imported oil, and energy security and environmental problems have become increasingly severe.

Desalination has become an important open-source way, and the main process of desalination technology are: Multi-stage flash (MSF): mature technology, rich operating experience, huge energy consumption, expensive. Multiple effect distillation (MED): high performance ratio, low energy consumption, high water production quality. Reverse permeable membrane (RO): simple process, less investment; producing water with low-quality, high requirements of permeable membrane.

Therefore, low power, high efficiency and high performance-cost ratio will become a major design goal. Meanwhile, for the product catering to small users, it should also have the features of small, simple structure and easy disassembly maintenance.

This system can have highly efficient absorption of solar with collectors of a biaxial automatic optical tracker system and checking system, and take solar energy as a source to heat the original seawater, and produce fresh water by distillation principle. The water level adjustment tank can supply the generating device automatically and control the water level, and make sea water tile as a thin layer, to increase the evaporation area and the evaporation rate, so that less solar at twilight can also be fully utilized. The designed coil heat exchanger uses latent heat of steam condensation to preheat the original seawater, to reduce the waste of energy and achieve efficient use of energy cascade.

\section{Work Process and device characteristics}

The apparatus is shown in Fig.1. After getting into the seawater tank (4), the seawater enters the 
generating means (2) after filtration through the filter (5), and the water level adjustment tank (8) uses the principle of communicating vessels to control the water level in generating means, so that the seawater paves a thin layer. After absorbing the heat provided by water dish collector (1), seawater gets the phase change to generate steam, and the steam gets into the coil heat exchanger (6) through a steam pipe (3), by heat exchange with the cold seawater to condense into fresh water and gets into the fresh water tank (9) by gravity. At the bottom of the fresh water box, some fresh water is pre-loaded, so that the bottom end of the collection tube is immersed in water to form a liquid seal. When it is used, we should first fill the seawater tank with seawater, and then turn on the electric source, the system automatically starts working.

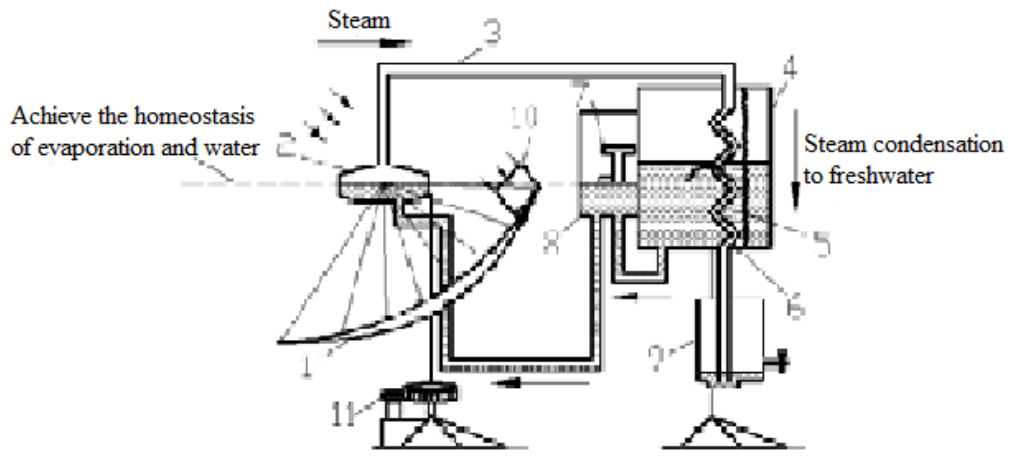

Fig.1 Schematic diagram of low-power fresh water extraction device of automatic replenishment 1- Heat collector, 2-Generating means, 3 Steam pipe, 4 Seawater tank, 5 Filter, 6-Coil heat exchanger, 7- Retractable inlet valve, 8-Water level adjustment tank, 9 Fresh water tank, 10-Light acquisition module, 11-Tracking light machine modules The device characteristics include the following aspects:

Structural features: Adopt an open heat pipe design with high efficiency, and it can automatically run without external power.

Low energy consumption: The system consumes renewable solar energy with the heat exchanger at the same time, which is not only to achieve efficient use of energy cascade, but also conducive to energy conservation and environmental protection.

High efficiency: Based on the distillation method, through a thin layer of seawater to increase the evaporation area and improve the evaporation rate.

Supply water automatically: Use water level adjustment tank instead of traditional valve to supply water automatically and control water level so that water evaporation and water supplement make dynamic equilibrium, so that the system runs continuously.

\section{Mathematical model}

Calculation parameters:Ambient temperature $T_{1}$, Seawater specific heat capacity $C_{p}$, Seawater latent heat of vaporization.

1. Cross-sectional area of the solar energy collection device.

2. Cross-sectional area of light for solar energy collection device $A_{\mathrm{c}}\left(A_{\mathrm{c}}=A\right)$.

3. Seawater flow into the collector device $Q_{2}$ (Known).

4. Thermal efficiency of the evaporation process for heat collector $N_{1}$, correction factor of steam pipe loss $N_{2}$, correction factor of coil type heat exchanger tank loss $N_{3}$, correction factor of seawater tube for the $N_{4}$

5. Variation of solar radiation $I_{\mathrm{b}}$ over time within a day: $I_{\mathrm{b}}=f(t)$.

Mathematical model of the device:

Useful power of cookers $P$ : 


$$
\mathrm{P}(\mathrm{t})=A_{c} I_{b} N_{1}=A_{c} N_{1} f(\mathrm{t})
$$

Energy balance equation of heat exchanger:

$$
\mathrm{P}(\mathrm{t}) N_{2} N_{3}=Q_{2} C_{p}\left(T_{2}-T_{1}\right)
$$

Where, seawater inlet temperature of heat exchanger is $T_{1}$, outlet temperature of seawater is $T_{2}$, seawater temperature of evaporator device is $T_{3}$,Correction equation of seawater piping loss:

$$
\begin{aligned}
& \mathrm{P}(\mathrm{t}) N_{2} N_{3} N_{4}=Q_{2} C_{p}\left(T_{2}-T_{1}\right) \\
& T_{3}=\frac{\mathrm{P}(\mathrm{t}) N_{2} N_{3} N_{4}}{Q_{2} C_{p}}+T_{1}
\end{aligned}
$$

Evaporator evaporation:

$$
\begin{aligned}
& \mathrm{P}(t) N_{1}=Q_{2} C_{p}\left(100-T_{3}\right)+Q_{0} r \\
& Q_{0}(t)=\frac{\mathrm{P}(t) N_{1}-Q_{2} C_{p}\left(100-T_{3}\right)}{\mathrm{r}}=\frac{\mathrm{P}(t)\left(N_{1}+N_{2} N_{3} N_{4}\right)-Q_{2} C_{p}\left(100-T_{1}\right)}{\mathrm{r}}
\end{aligned}
$$

One day evaporation:

$$
\begin{aligned}
& \mathrm{M}=\int_{0}^{t} \mathrm{Q}_{0}(t) d t=\int_{0}^{t} \frac{\mathrm{P}(t)\left(N_{1}+N_{2} N_{3} N_{4}\right)-Q_{2} C_{p}\left(100-T_{1}\right)}{\mathrm{r}} d t \\
& \mathbf{M}=\int_{0}^{\mathrm{t}} \mathrm{Q}_{0}(\mathrm{t}) \mathrm{dt}=\int_{0}^{\mathrm{t}} \frac{\mathrm{P}(\mathrm{t})\left(\mathrm{N}_{1}+\mathrm{N}_{2} \mathrm{~N}_{3} \mathrm{~N}_{4}\right)-\mathrm{Q}_{2} \mathrm{C}_{\mathrm{P}}\left(100-\mathrm{T}_{1}\right)}{\mathrm{r}} \mathrm{dt}
\end{aligned}
$$

\section{Design calculation}

Known: Time: summer solstice, Location: Beijing (latitude $40.22^{\circ} \mathrm{N}$ )

Operating hours: 8: 00-16:00.

Solar elevation angle $B \quad\left(37^{\circ}--73^{\circ}--37^{\circ}\right)$, Solar azimuth $A\left(90^{\circ}-0^{\circ}--90^{\circ}\right)$.

Ambient temperature: $30^{\circ} \mathrm{C}$, seawater parameter $C_{\mathrm{p}}=4.18 \mathrm{~kJ} /(\mathrm{kg} \cdot \mathrm{k})$, Latent heat of vaporization $\mathrm{r}=2257.1 \mathrm{~kJ} / \mathrm{kg}$.

Cross-sectional area of the solar energy collection deviceA $=2.5 \mathrm{~m}^{2}$, Cross-sectional area of light for solar energy collection device $\mathrm{A}_{\mathrm{c}}=2.5 \mathrm{~m}^{2}$.

Take the water flow into the evaporation apparatus $\mathrm{Q}_{2}=0.002 \mathrm{~kg} / \mathrm{s}$.

The thermal efficiency of the evaporation process for heat collector $N_{1}$, correction factor of steam pipe loss $N_{2}$, correction factor of coil type heat exchanger tank loss $N_{3}$, Seawater piping correction factor $N_{4}$ is $90 \%$.

The average direct solar irradiance $I_{\mathrm{b}}$ : take $I_{\mathrm{b}}=800 \mathrm{~W} / \mathrm{m}^{2}$.

Solving: Useful power of cookers $\mathrm{P}=A_{\mathrm{C}} I_{\mathrm{b}} N_{1}=1800 \mathrm{w}$

Energy balance equation of heat exchanger: 


$$
\begin{aligned}
& P(t) N_{2} N_{3}=Q_{2} C_{p}\left(T_{2}-T_{1}\right) \\
& T_{2}=P(t) N_{2} N_{3}+T_{1}
\end{aligned}
$$

Evaporation of steam vaporizer:

$$
Q_{0}(t)=\frac{\mathrm{P}(t)\left(N_{1}+N_{2} N_{3} N_{4}\right)-Q_{2} C_{p}\left(100-T_{1}\right)}{\mathrm{r}}=0.00104 \mathrm{~kg} / \mathrm{s}
$$

One day evaporation $M=Q_{0} * 3600 * 8=30 \mathrm{~kg}$

\section{Experiment analysis and application future}

According to experiments, the average water yield of the device is $0.40 \mathrm{~mL} / \mathrm{s}$ in Beijing in June, the peak is up to $0.66 \mathrm{~mL} / \mathrm{s}$, the water production from eight a.m. to four p.m. is calculated about $11520 \mathrm{ml}$. The average daily water demand for one adult is $2500 \mathrm{ml}$ or more, of which about 1500 to $2000 \mathrm{ml}$ is drinking water directly, and the remaining from the food intake. After calculating, it can meet 7.68 people's need in drinking water. If domestic water is used, the case may need to reduce. Features: Simple and practical, high quality, automates the process of desalination, easy disassembly and maintenance and cleaning, stable and reliable performance.

Market analysis: It can basically meet the demand of residents in small islands and small-scale population coastal areas for fresh water. Meanwhile, if the fixed measures is adopted, it will have great appeal for offshore vessels, fishing vessels and other user groups.

\section{References}

[1] Yang S, Tao W. Heat Transfer (the fourth edition), Higher Education Press, 2006.8. (In Chinese)

[2] Ren H, Chen X. Solar cooker technology, Chemical Industry Press, 2006.9. (In Chinese)

[3] Shi Y. Solar principle and technology, Xi'an Jiaotong University Press, 2009.8. (In Chinese)

[4] Wang S. Seawater Desalination Engineering, Chemical Industry Press, 2003.3. (In Chinese) 